\title{
Design of a Wide Input Range DC-DC Converter Suitable for Lead-Acid Battery Charging
}

\author{
M.W.D.R. Nayanasiri and J.A.K.S.Jayasinghe, B.S. Samarasiri
}

\begin{abstract}
In this paper design and implementation of a wide input range Cascaded Buck and Boost (CBB) converter is presented with a robust power controller. Four new control strategies are proposed and tested for this converter based on input voltage and duty cycle of the control signals. Robust feature of the proposed control system ensures constant output DC current required to charge the Lead-Acid batteries in bulk charge mode. The robust feedback controller of the power converter is developed using a microcontroller which is acting as smart controller of the CBB converter.

DC-DC converters which are used for battery charging applications with variable power sources should be able to both step-up and step-down the input voltage and provide high efficiency in the whole range of operation. The CBB converter with power switches and diodes is used to achieve above objective. CBB converter is constructed by cascading a Buck and a Boost Converter and eliminating the output capacitor of the buck converter.
\end{abstract}

Keywords: Cascaded Buck and Boost Converter, Microcontroller, Lead Acid Batteries

\section{Introduction}

DC-DC converters with step-up and step-down capability are required in several applications where the input and output voltage ranges overlap. As an example, in the battery charging application which uses variable input power sources such as wind mills and motorgenerator units of the hybrid vehicles. Topologies such as Inverted Buck-Boost converter and Single Ended Primary Inductance Converters (SEPIC) can be used to obtain constant output voltage from variable power sources [1]. But they have low efficiency, high output ripple, high noise and spikes in the output voltage. Hence they are not suitable to implement power supplies for battery charging applications.

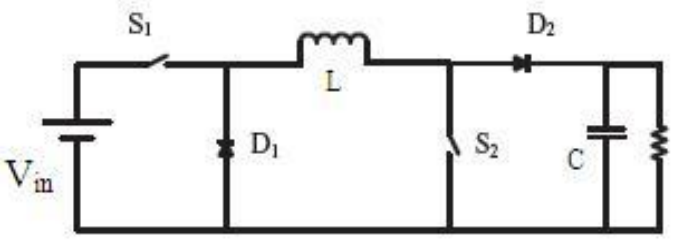

Figure 1 - Cascaded Buck and Boost Converter A DC-DC power converter is constructed by cascading Buck and Boost Converter and eliminating the output capacitor of the Buck Converter as shown in Figure 1.

This DC-DC converter has minimum components, low component stresses and low energy storage capability in order to have small size and high efficiency.
There are four possible switching states in a CBB converter topology. They are shown in Table 1 .

Table 1- Switching States of CBB

\begin{tabular}{|c|c|c|c|}
\hline $\begin{array}{c}\text { Switching } \\
\text { State }\end{array}$ & S1 & S2 & Mode \\
\hline 1 & ON & PWM & Boost \\
\hline 2 & PWM & PWM & Buck-Boost \\
\hline 3 & OFF & PWM & N/A \\
\hline 4 & PWM & OFF & Buck \\
\hline
\end{tabular}

In the buck mode $V_{\text {out }} \simeq V_{\text {in }}$, when duty cycle of the gate control signal is close to unity. But it is difficult to have duty cycle of the gate control signal of the power MOSFETs close to unity due to the switching limitations of the available power switches and their gate drive technologies.

In boost mode of operation $V_{\text {out }} \simeq V_{\text {in }}$ occurs when duty cycle is close to zero. With existing gate drive technologies of the power MOSFETs, it is also difficult to have duty cycle close to zero.

Hence CBB converter cannot be operated satisfactorily when $\mathrm{D}<0.1$ and $\mathrm{D}>0.95$ for boost and buck mode respectively. Therefore we get a dead band as shown in Figure 2.

\footnotetext{
Eng. Dulika Nayanasiri, BSc Eng.(Hons), AMIE(Sri

Lanka), Formerly Research Engineer, Engineering Design Centre, University of Moratuwa. Presently PhD candidate NTU, Singapore.

Eng. (Prof.) J A K S Jayasinghe, BSc Eng. (Hons),

MEng., CEng., PhD, MIE(Sri Lanka), Presently, Senior

Professor, Dept. of Electronics Engineering, University of

Moratuwa.
} 
In buck-boost mode, $V_{\text {out }} \simeq V_{\text {in }}$ occurs when duty cycle of the power switches is close to 0.5 . This range of the duty cycle can achieve easily with existing MOSFET gate drive technology. Therefore buck-boost mode is used to transfer power within the above dead band.

Efficiency wise, it is not advantageous to operate this converter in buck-boost mode [2]. But in order to smooth the transients, the buckboost mode is used to transit from buck mode to boost mode or vice versa [3], [1]. Hence four control algorithms are developed for this CBB converter to obtain smooth transition between each operation modes.

The proposed four control algorithms for this converter are based on the duty cycle of the gate control signal, input voltage and output current.

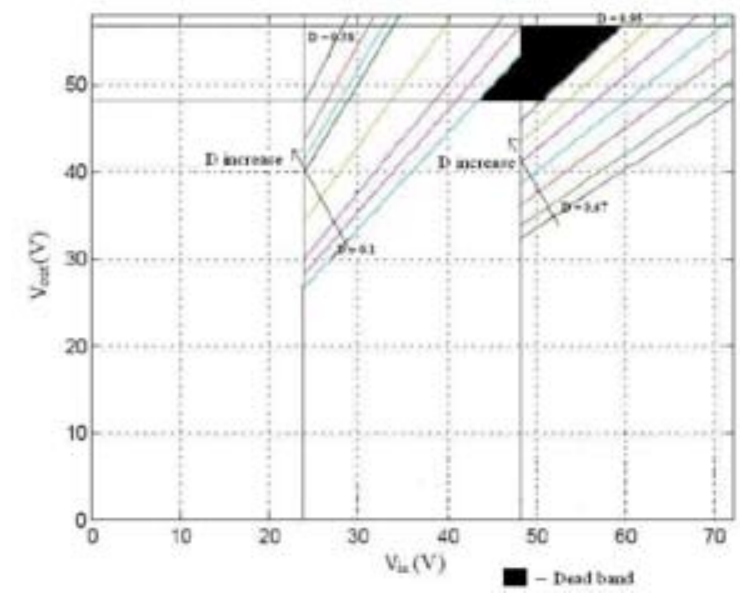

Figure 2 - Dead zone present in the output voltage

This paper organizes as follows. The next section explains the proposed new control algorithm for this converter. Section 3 provides the specifications of the converter. In Section 4 the operation modes with switches is explained and in Section 5, the system architecture is explained in brief. Section 6 provides design and implementation details with relevant calculations. In section 7 , experiment setup is presented and in the next section results obtained from the experiment are given.

\section{Control Strategy}

Control strategy of the controller is for maintaining a constant output current from the $\mathrm{CBB}$ converter as the converter load and input voltage changes. Main control is implemented by using a microcontroller. Closed loop control is used to develop firmware. Switching the CBB converter between buck, buck-boost and boost modes is a complex task as transients play a major role as this mode of operation changes.
Control algorithm of the converter is based on the duty cycle of the control signal, input voltage and output current.

Input voltage based control strategy is proposed in [1] for this type of converters. But, such control algorithms are not possible to use in this converter as the output load of this converter is changing while the battery pack is being charged.

Hence, four new control algorithms are proposed for this converter by taking input voltage and duty cycle of the power switch control signals as control parameters.

\subsection{Control strategy 1 - Input voltage based control strategy with zero initial duty cycle}

In this algorithm, mode of operation of the CBB converter is decided using only the input voltage. The gate control signal of the power switches are initialized with zero duty cycle.

\subsection{Control strategy 2 - Input voltage based control strategy with non-zero initial duty cycle}

In this algorithm, mode of operation of the CBB converter is decided using input voltage. The gate control signal of the power switches are initialized with non-zero duty cycle. The duty cycle of the power switch is calculated to give minimum dips in the output current as the converter changes its mode of operation.

\subsection{Control strategy 3 - Input voltage and duty cycle based control strategy}

Initial mode of operation of the converter is decided using input voltage. Use input voltage as the control parameter to transit from buckboost mode to buck mode or from buck-boost mode to boost mode. Duty cycle of the control signal is used as the control parameter when it is required to transit from boost mode to buckboost mode or from buck mode to buck-boost mode.

\subsection{Control strategy 4 - Duty cycle based control strategy}

In this control algorithm, initial mode of operation is decided based on the input voltage. Subsequently controller changes its mode of operation according to the maximum and minimum allowable duty cycle in each mode of the CBB converter. 


\section{Specifications}

CBB converter is developed to charge the $48 \mathrm{~V}$ Lead-Acid battery pack. There are four modes in the standard Lead-Acid battery charging cycle namely: trickle charge, bulk charge, over charge and float charge. In this application, bulk charge mode is used to charge the battery pack with constant current. According to the battery standard, to charge the Lead-Acid battery in bulk charging mode, battery pack should be charged with a current rated to $10 \%$ $30 \%$ of the battery capacity. As 65Ah Lead-Acid batteries are used in this design, charging current was set to $6 \mathrm{~A}$.

Bulk charge mode of the Lead-Acid battery charging cycle ends up when the cell terminal voltage reaches $2.26 \mathrm{~V}$ or $2.36 \mathrm{~V}$ [4]. Therefore terminal voltage of the battery pack will be $56.64 \mathrm{~V}$ at the end of bulk charge mode. Hence the output voltage of the CBB converter should vary from $48 \mathrm{~V}$ to $56.64 \mathrm{~V}$.

Table 2 - Summary of Specifications of CBB

\begin{tabular}{|c|c|}
\hline Description & Value \\
\hline I/P voltage range & $24 \mathrm{~V}-72 \mathrm{~V}$ \\
\hline O/P voltage range & $48 \mathrm{~V}-56.64 \mathrm{~V}$ \\
\hline O/P current & $6 \mathrm{~A}$ \\
\hline O/P current ripple & Max. $1 \mathrm{~A}$ \\
\hline
\end{tabular}

\section{Modes of Operation}

CBB converter topology is supported for three modes of operation. In this application all three modes were implemented, inclusive of the positive buck-boost mode. Positive buck-boost mode acts as a bridge to transit from the buck mode of operation to boost mode or vice versa by providing ability to transfer the power when $V_{\text {in }} \approx V_{\text {out }}$.

The equivalent circuit of the $\mathrm{CBB}$ converter is shown in Figure 3. The converter consists of input capacitor $C_{i n}$, output filter capacitor $C_{\text {out }}$, two power switches $Q_{1}$ and $Q_{2}$, inductor $L$ and two freewheeling diodes $D_{1}$ and $D_{2}$. The forward voltage drop of the diode is $V_{\mathrm{fw}}$.

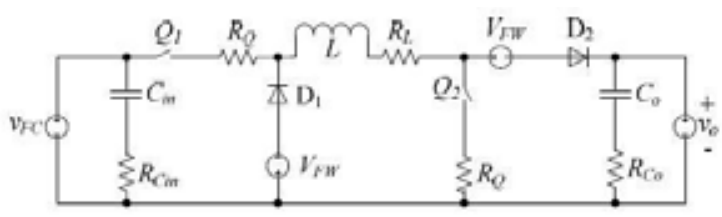

Figure 3 - Equivalent circuit of CBB converter
All modes are operated at the same frequency represented by $=\frac{1}{T}$. Figure 4 depicts typical control signal provided by the microcontroller.

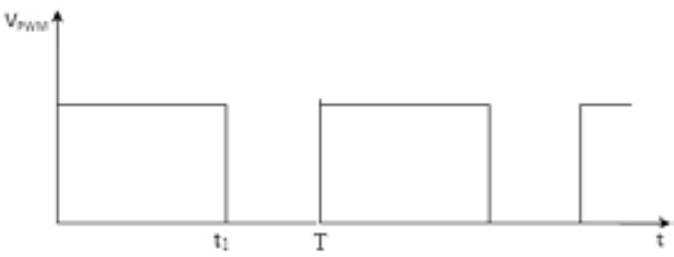

Figure 4 - Control signal of power switches

\subsection{Buck Mode}

If input voltage is greater than the output voltage or terminal voltage of the battery pack, buck mode is used. In this mode of operation, $\mathrm{Q}_{1}$ is controlled by the Pulse Width Modulated (PWM) signal as shown in Figure 4 and $\mathrm{Q}_{2}$ is always in OFF condition. With switching frequency $f$ and duty cycle $D=\frac{t_{1}}{\tau}$, input and output voltage relationship is given by equation (1).

$$
V_{\text {out }}=\frac{t_{1}}{T} \cdot V_{\text {in }}=D \cdot V_{\text {in }}
$$

This was derived by neglecting $\mathrm{V}_{\mathrm{fw}}, \mathrm{ON}$ switch resistance of $\mathrm{Q}_{1}$ and inductor resistance. The inductor current $\left(\mathrm{I}_{\mathrm{L}}\right)$ has a triangle shape and its average value is determined by the load. The peak-to-peak current ripple $\Delta \mathrm{I}_{\mathrm{L}}$ is dependent on $\mathrm{L}$ and can be calculated with the help of equation (2) [5].

$$
\Delta \mathrm{I}_{\mathrm{L}}=\frac{1}{\mathrm{~L}} \cdot\left(V_{\text {iv }}-V_{\text {out }}\right) \cdot \frac{V_{\text {out }}}{V_{\text {in }}} \cdot \frac{1}{f}
$$

\subsection{Boost Mode}

If input voltage is less than the terminal voltage of the battery pack, then boost mode of operation is used to step-up the voltage input in order to charge the battery. In this mode of operation, $Q_{1}$ is always $O N$ and $Q_{2}$ is controlled by the PWM signal provided by the main controller as shown in Figure 4. The relationship between input and output voltage can be derived by neglecting diode forward voltage drop $\mathrm{V}_{\mathrm{fw}}$, switch $\mathrm{ON}$ resistance and inductor resistance. For a switching frequency $f$ and duty cycle $D=\frac{t_{1}}{\tau}$, then $\mathrm{V}_{\text {out }}$ is given by equation (3),

$$
V_{\text {out }}=\frac{T}{T-t_{1}} \cdot V_{\text {in }}=
$$


The inductor ripple current is given by equation (4) [5],

$$
\Delta \mathrm{I}_{\mathrm{L}}=\frac{1}{\mathrm{~L}} \cdot\left(V_{\text {out }}-V_{\text {in }}\right) \cdot \frac{V_{\text {in }}}{V_{\text {out }}} \times \frac{1}{f}
$$

\subsection{Buck-Boost Mode}

This mode is used when $V_{\text {out }} \simeq V_{\text {in }}$. In this mode input and output voltage relationship is given by equation (5).

$$
V_{\text {out }}=\frac{t_{1}}{T-t_{1}} \cdot V_{\text {in }}=\frac{D}{1-D} \cdot V_{\text {in }}
$$

Both power switches are controlled by PWM signals having same duty cycle D. During the time $t_{1}$ both switches conduct simultaneously and during the time $T-t_{1}$ both switches are OFF and the energy stored in the inductor is released to the load.

\section{System Architecture}

CBB converter is constructed as a combination of different subsystems namely: input voltage monitor, output voltage monitor, output current monitor, power supply, main controller and main power path or CBB converter. This is shown in Figure 5.

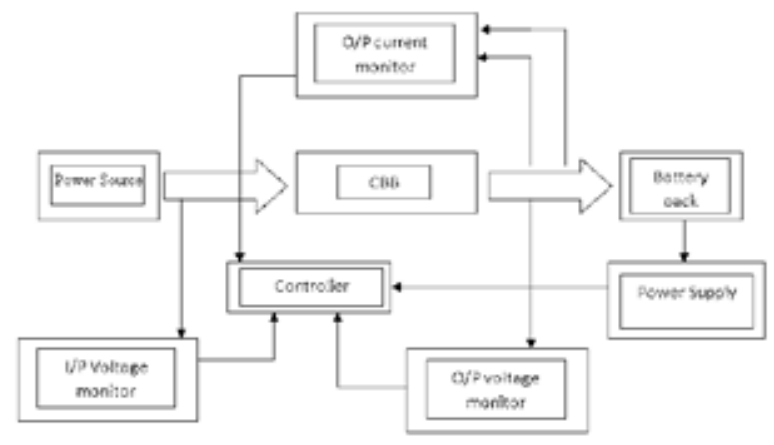

Figure 5 - System Architecture

Input and output voltage monitor subsystems are implemented using voltage followers and output current monitor subsystem is implemented using a differential amplifier. Power supply of the converter is based on linear power regulators and transistor voltage regulator.

Switching frequency of the CBB is selected by considering inductor size and the power MOSFETs switching losses [6]. With higher switching frequency $f$, size of the inductor will be small. But the switching losses of the power MOSFETs become larger as $f$ increases. Hence operation frequency of the CBB is selected as
$15.625 \mathrm{kHz}$ because this value can be easily obtained from maximum PWM register value with $4 \mathrm{MHz}$ crystal.

\section{Design and Implementation}

Same inductor (L) and same output filter capacitor $\left(\mathrm{C}_{\text {out }}\right)$ are used in all modes of operation of the CBB. Hence in the design process, the required inductor and output capacitor values for all modes of operation are calculated using equations (9) (11), (16) and (18). Then select the maximum value of inductor and capacitor which is calculated using above equations, as minimum inductor and capacitor value of the CBB converter.

\subsection{Buck Mode}

In this mode, maximum input voltage is $72 \mathrm{~V}$ and minimum output voltage is $48 \mathrm{~V}$. Hence maximum duty cycle is

$$
\begin{gathered}
D_{\max }=\frac{V_{\text {out }}}{V_{\text {in }}}=\frac{49}{72} \\
D_{\max }=0.667
\end{gathered}
$$

If the maximum allowable output ripple current is $\Delta \mathrm{I}_{\mathrm{L}}=0.2 I_{\text {o }}$.

$$
\Delta \mathrm{I}_{\mathrm{L}}=.2 I_{0}=.2 \times 6=1.2 \mathrm{~A}
$$

Therefore the minimum required inductor, in order to obtain continues conduction mode at the rated output current is given by equation (9).

$\mathrm{L}=\frac{1}{\Delta \mathrm{I}_{\mathrm{L}}} \cdot\left(\mathrm{V}_{\text {in }}-\mathrm{V}_{\text {out }}\right) \cdot \frac{\mathrm{V}_{\text {out }}}{\mathrm{V}_{\text {in }}} \times \frac{1}{\mathrm{f}}=0.853 \mathrm{mH}$

The current ripple $\Delta \mathrm{I}_{\mathrm{L}}$ causes a voltage ripple $\Delta \mathrm{V}_{\text {out }}$ at the output capacitor $\mathrm{C}_{\mathrm{o}}$. For normal switching frequencies, this voltage ripple is determined by the equivalent impedance $Z_{\max }$. The capacitors used for our design were obtained from the local market and their technical details were not available. Therefore the capacitor values were selected to give minimum output ripple current using trial and error method.

The approximate value for the output capacitor can be found using equation (10) [2],

$$
\mathrm{C}_{\text {min }}=\frac{\mathrm{P}_{\text {rated }}}{\mathrm{fW}_{\mathrm{A}} \Delta \mathrm{V}_{\mathrm{a}}}
$$

This is assuming that $\Delta \mathrm{V}_{\mathrm{o}}=0.01 \mathrm{~V}_{\mathrm{o}}$ and rated power output of the converter approximately equals to $260 \mathrm{~W}$. 
$\mathrm{C}_{0, \min }=\frac{260}{15,625 \times 10 \times 49 \times 48}=722 \mu \mathrm{F}$

\subsection{Boost Mode}

In this mode, minimum input voltage is $24 \mathrm{~V}$ and maximum output voltage is $56 \mathrm{~V}$. Hence maximum duty cycle is,

$$
D=1-\frac{V_{\text {in }}}{V_{\text {out }}}=0.5
$$

If maximum allowable output ripple current is $\Delta \mathrm{I}_{\mathrm{L}}=0.2 \mathrm{I}_{\text {in, }}$ the input current $\mathrm{I}_{\text {in }}$ can be calculated by assuming zero losses $\left(P_{\text {in }}=P_{\text {out }}\right)$, Therefore:

$$
\begin{aligned}
& V_{\text {in }} \cdot I_{\text {in }}=V_{\text {out }} I_{\text {out }} \longrightarrow I_{\text {in }}=\frac{V_{\text {out }}}{V_{\text {in }}} . I_{\text {out }} \\
& I_{\text {in }}=\frac{56}{24} \times 5=11.66 \mathrm{~A}
\end{aligned}
$$

The inductors ripple current $\Delta \mathrm{I}_{\mathrm{L}}$ is given by equation (15).

$$
\Delta \mathrm{I}_{\mathrm{L}}=0.2 \times 11.66 \mathrm{~A}=2.334 \mathrm{~A}
$$

Therefore the minimum required inductor to obtain continues conduction mode at the rated output current is given by equation (16)

$$
\mathrm{L}=\frac{1}{\Delta \mathrm{I}_{\mathrm{L}}} \cdot\left(\mathrm{V}_{\text {out }}-\mathrm{V}_{\text {in }}\right) \cdot \frac{\mathrm{V}_{\text {in }}}{\mathrm{V}_{\text {out }}} \times \frac{1}{\mathrm{f}}=0.376 \mathrm{mH}
$$

By using equation (17) [2], the required output filter capacitor can be found using equation (17)

$$
\mathrm{C}_{\text {min }}=\frac{\mathrm{P}_{\text {rated }}}{\mathrm{fV} \Delta \mathrm{V}_{\mathrm{a}}}
$$

This is assuming that $\Delta \mathrm{V}_{\mathrm{o}}=0.01 \mathrm{~V}_{\mathrm{o}}$ and rated power output of the converter is approximately 260W.

$$
\mathrm{C}_{0, \min }=\frac{260}{15,625 \times 10 \times 56 \times 56}=530 \mu \mathrm{F}
$$

\subsection{Buck-Boost Mode}

This mode is used in the limited input voltage range $(48 \mathrm{~V}-56 \mathrm{~V})$. In this mode, $V_{\text {out }} \simeq V_{\text {in }}$ condition is given by the duty cycle of the PWM signals in the range of $0.4<D<0.6$.

Buck-boost mode is developed on the same physical setup is used to develop buck and boost modes and therefore same inductor and capacitor is used.

According to above calculations, the minimum inductor value was selected as $0.853 \mathrm{mH}$ and minimum output capacitor as $740 \mu \mathrm{F}$. All above calculations were performed with approximations and therefore those minimum valued components do not give the required performance. Inductor was chosen as $3.48 \mathrm{mH}$ and output capacitor as $4700 \mu \mathrm{F}$.

Two switching transistors $\mathrm{Q}_{1}$ and $\mathrm{Q}_{2}$ are realized with N-channel MOSFETs (IRFP250) having $0.085 \Omega$ on resistance, $200 \mathrm{~V}$ break down voltage, 33A maximum average current and nanosecond switching speed. In order to drive high side and low side N-channel MOSFETs, MOSFET gate drive IC (IR2101) based on bootstrap gate drive technology was used.

BYW29E low forward voltage drop (0.895V) fast switching rectifier diode was selected as $D_{1}$ and $\mathrm{D}_{2}$. It has $200 \mathrm{~V}$ peak reverse voltage and 8 A continues forward current.

At the end of the design stage, the CBB converter was implemented and the test setup is shown in Figure 6.

\section{Experimental setup}

The proposed converter and control algorithm are implemented in a laboratory prototype. The performance of the buck mode and boost mode were tested separately. Then both modes were tested together against whole range of input voltage with the main controller of the CBB.

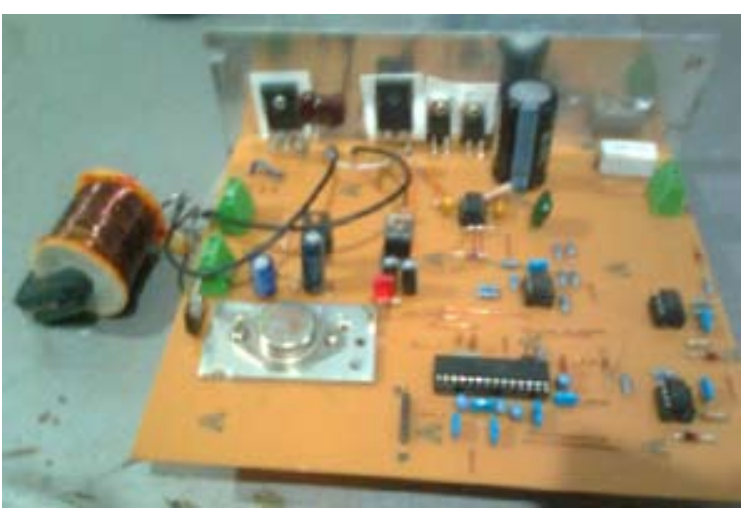

Figure 6 - DC-DC converter test setup

During the test, the dead band was clearly visible in the output voltage. In order to overcome this problem, buck-boost mode was developed using same test setup by modifying the firmware.

In the buck-boost mode, switching transistor Q1 is switched with duty cycle slightly higher than that of switching transistor $Q_{2}$ due to switching limitation of the power switches.

Finally all three modes were tested in the same test setup with modified main controller firmware. 


\section{Results}

The results given below correspond to a $260 \mathrm{~W}$ prototype with a switching frequency of 15.625 KHz.

First, the CBB converter was tested with control strategy 1 which is based on the input voltage. In this method, converter changes its mode of operation from boost to buck-boost and then to buck mode as the input voltage increases or other way as input voltage decreases. When converter changes its mode of operation, there were significant voltage dips in the output voltage and hence a discontinuity appeared in the output current as shown in Figure 7.

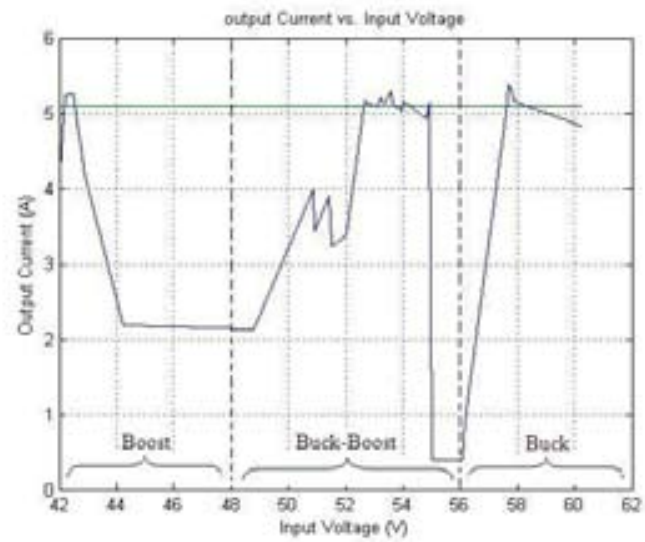

Figure 7 - Output current vs. Input voltage with control strategy 1.

Then the CBB converter was tested with modified control algorithm (Control strategy 2), with an initial none zero duty cycle for the control signals. An improvement was observed in the output current as shown in Figure 8.

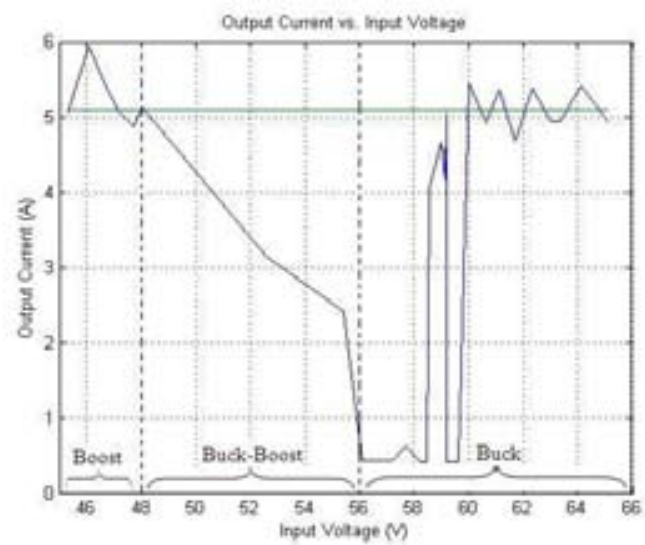

Figure 8 - Output current vs. Input voltage with control strategy 2.

Next the CBB converter was tested with control strategy 3 based on duty cycle and input voltage based. Dips in the output voltage and discontinuity in the output current were improved with this control strategy and the results are shown in Figure 9.

It was observed that the converter operates in the buck-boost mode within a large input voltage range. But the operation of the converter in the buck-boost mode is not efficient.

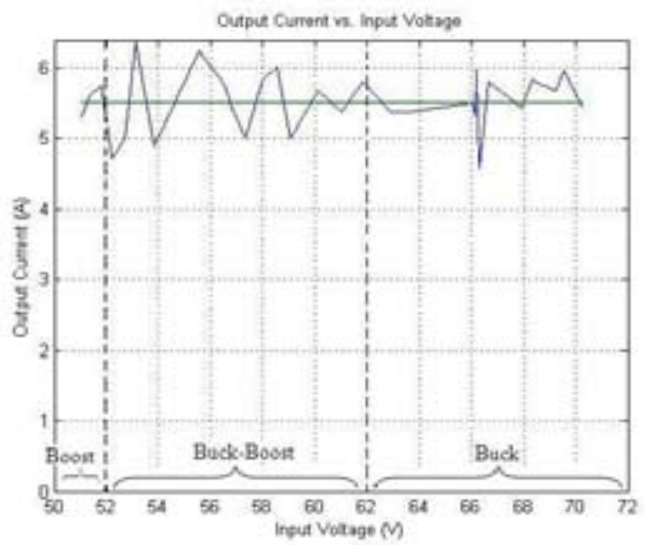

Figure 9 - Output current vs. Input voltage with control strategy 3.

To overcome the deficiencies in control strategy 3 , the CBB converter was tested with a control strategy which is completely based on the duty cycle of the MOSFETs control signals (Control strategy 4). With this control strategy, it was possible to solve the issues related to output voltage dips, output current discontinuity and operation voltage range. The results are shown in Figure 10.

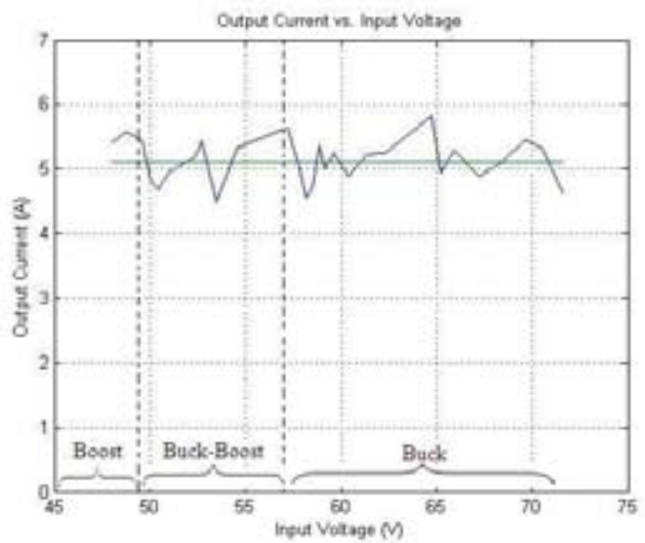

Figure 10 - Output current vs. Input voltage with control strategy 4.

The CBB converter based on control strategy 4 was used to charge the 65Ah Lead-Acid battery pack with $5.5 \mathrm{~A}$ constant current by varying input voltage from $24 \mathrm{~V}$ to $72 \mathrm{~V}$. It was observed that, this converter can be operated in pure buck and boost modes with high efficiency and in the non inverted buck-boost mode with a lower efficiency. 
Battery terminal voltage was measured with time while charging the battery pack using boost mode and varying input voltage from $24 \mathrm{~V}$ to $40 \mathrm{~V}$. Results are plotted in Figure 11.

\section{Conclusion}

In this paper steady-state behaviour of the CBB converter is analysed and presented. The equations are derived for the buck mode and boost mode, when the converter is implemented with diodes and power switches. Selection of components and implementation details are also presented. This converter is suitable for applications which require non inverted step-up and step-down operation in a single circuit with low component count, low component stress, simplicity and high efficiency.

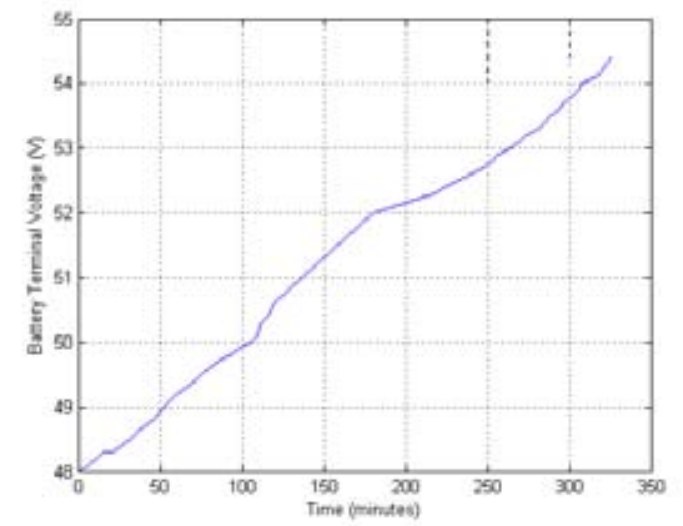

Figure 11 - Battery Terminal Voltage vs. Time

Although this converter is not efficient [2] in the buck-boost mode, show the importance of buck-boost mode to transfer power when $V_{\text {out }} \simeq V_{\text {in }}$ in the application having overlapped input and output voltage range.

Duty cycle based control strategy is more suitable to change the mode of operation of the $\mathrm{CBB}$ converter other than the input voltage based control strategies.

\section{Acknowledgement}

The authors would like to thank Ministry of Industry and Commerce (Formerly Ministry of Industrial Development) in Sri Lanka for the financial support for this work through the Development of Hybrid three wheeler project. Special thank would go to the staff of the Engineering Design Centre of University of Moratuwa.

\section{References}

1. Chakraborty, A., Khaligh, A. and Emadi, A, "Combination of Buck and Boost Modes to Minimize Transients in the Output of a Positive Buck Boost Converter" 32nd Annual IEEE Conference on Industrial Electronics Nov. 2006.

2. Schaltz Erik, Khaligh Alireza "Non-inverting Buck-Boost Converter for Fuel Cell Applications" June 2008.

3. Gaboriault, $\mathrm{M}$ and Notman, $\mathrm{A}$ "A High Efficiency, Non Inverting, Buck Boost DC-DC Converter" Applied Power Electronics Conference and Exposition, pp. 1411-1415, 2004.

4. Oconnor, John A, "Simple Switch mode Lead-Acid Battery Charger"

5. Heinz Schmidt Walter "Switched Mode Power Supplies"

6. http://schmidt-walter.eit.h-da.de/ 
